\title{
Organic particle types by single-particle measurements using a time-of-flight aerosol mass spectrometer coupled with a light scattering module
}

\author{
S. Liu ${ }^{1, *}$, L. M. Russell ${ }^{1}$, D. T. Sueper ${ }^{2,3}$, and T. B. Onasch ${ }^{3,4}$ \\ ${ }^{1}$ Scripps Institution of Oceanography, University of California, San Diego, La Jolla, California, USA \\ ${ }^{2}$ Cooperative Institute for Research in Environmental Studies, University of Colorado, Boulder, Colorado, USA \\ ${ }^{3}$ Center for Aerosol and Cloud Chemistry, Aerodyne Research Inc., Billerica, Massachusetts, USA \\ ${ }^{4}$ Chemistry Department, Boston College, Chestnut Hill, Massachusetts, USA \\ *now at: Earth Systems Observations Los Alamos National Lab, Los Alamos, New Mexico, USA
}

Correspondence to: L. M. Russell (lmrussell@ucsd.edu)

Received: 27 February 2012 - Published in Atmos. Meas. Tech. Discuss.: 25 April 2012

Revised: 15 December 2012 - Accepted: 30 December 2012 - Published: 1 February 2013

\begin{abstract}
Chemical and physical properties of individual ambient aerosol particles can vary greatly, so measuring the chemical composition at the single-particle level is essential for understanding atmospheric sources and transformations. Here we describe 46 days of single-particle measurements of atmospheric particles using a time-of-flight aerosol mass spectrometer coupled with a light scattering module (LS-ToF-AMS). The light scattering module optically detects particles larger than $180 \mathrm{~nm}$ vacuum aerodynamic diameter $(130 \mathrm{~nm}$ geometric diameter) before they arrive at the chemical mass spectrometer and then triggers the saving of single-particle mass spectra. 271641 particles were detected and sampled during $237 \mathrm{~h}$ of sampling in singleparticle mode. By comparing timing of the predicted chemical ion signals from the light scattering measurement with the measured chemical ion signals by the mass spectrometer for each particle, particle types were classified and their number fractions determined as follows: prompt vaporization (46\%), delayed vaporization (6\%), and null (48\%), where null was operationally defined as less than 6 ions per particle. Prompt and delayed vaporization particles with sufficient chemical information (i.e., more than 40 ions per particle) were clustered based on similarity of organic mass spectra (using $k$ means algorithm) to result in three major clusters: highly oxidized particles (dominated by $m / z 44$ ), relatively less oxidized particles (dominated by $m / z 43$ ), and particles associated with fresh urban emissions. Each of the three organic
\end{abstract}

clusters had limited chemical properties of other clusters, suggesting that all of the sampled organic particle types were internally mixed to some degree; however, the internal mixing was never uniform and distinct particle types existed throughout the study. Furthermore, the single-particle mass spectra and time series of these clusters agreed well with mass-based components identified (using factor analysis) from simultaneous ensemble-averaged measurements, supporting the connection between ensemble-based factors and atmospheric particle sources and processes. Measurements in this study illustrate that LS-ToF-AMS provides unique information about organic particle types by number as well as mass.

\section{Introduction}

Rapid measurements are needed to accurately quantify atmospheric particle sources and compositions and to study their transformations. The aerosol mass spectrometer (AMS) is one fast-developing and widely used technique for monitoring size and composition of submicron particles in real time (Jayne et al., 2000). Quantified species include nonrefractory organic mass $(\mathrm{OM})$, sulfate, nitrate, ammonium, and chloride. Recent developments enable separation of ions that are slightly different in mass and overlap in unit-mass spectrum by replacing the quadrupole mass spectrometer (in 
Q-AMS) with a compact time-of-flight mass spectrometer (C-ToF-AMS), as described in Drewnick et al. (2005), and a high-resolution time-of-flight mass spectrometer (HR-ToFAMS), described in DeCarlo et al. (2006). The ToF-AMS collects signals from the composition of ensembles of particles in each chopper cycle. In the brute force single-particle (BFSP) mode of the ToF-AMS operation, mass spectrum extractions within a chopper cycle are saved, enabling acquisition of single-particle mass spectra. However, the BFSP mode is typically turned off during field measurements to conserve data storage and processing time. The only published analysis utilizing this mode came from field measurements made by Drewnick et al. (2005), whereby singleparticle mass spectra were acquired several times, each for a few minutes. These single-particle spectra were used to investigate internal and external mixing properties of submicron particles. Cross et al. (2007, 2009) advanced the AMS by coupling a light scattering module (LS-ToF-AMS) in which particles are optically detected by a laser before they reach the vaporizer. In LS-ToF-AMS, single-particle mass spectra are recorded during the operation of the light scattering single-particle (LSSP) mode. The LSSP mode is similar to the BFSP mode, except that particle light scattering signals trigger the saving of single-particle mass spectra, which considerably enhances the data transfer and saving efficiency compared to the BFSP mode operation, during which mass spectra in each chopper cycle are saved individually regardless of the existence of particles. The LS-ToF-AMS was successfully deployed during the MILAGRO (Megacity Initiative: Local and Global Research Observations) 2006 field campaign for a 75-h sampling period (Cross et al., 2009), demonstrating its unique ability to provide insights into the atmospheric transformations of ambient particles.

Compared to other single-particle measurement techniques (Table 1), the LS-ToF-AMS has the advantage of providing simultaneously quantified single- and ensembleparticle mass spectra, although the single-particle detection limit of the LS-ToF-AMS is higher than most of the online single-particle mass spectrometers (using laser ablation) and refractory components are not measured by LS-ToF-MS. Single-particle measurement statistics of LS-ToF-AMS are comparable to other online single-particle mass spectrometers and much greater than offline electron microscopy techniques, although the latter provide additional information about particle morphology and elemental composition.

This study expands the previous work of Cross et al. (2007, 2009) to identify three chemically distinguishable classes of particles with a 46-day field measurement using the LS-ToFAMS at a polluted urban site. We used the modified standard light scattering and single-particle mass spectra processing algorithm Sparrow and describe single-particle postprocessing procedures. To interpret the organic composition of the individual particles, we grouped single-particle mass spectra to reduce the large dataset into a few clusters, each with distinct characteristics.

\section{Measurements}

The LS-ToF-AMS (Aerodyne, Billerica, MA) was deployed from 15 May to 29 June 2010 at Bakersfield during the CalNex (California Research at the Nexus of Air Quality and Climate Change) field campaign. The instrument combines the well-characterized HR-ToF-AMS and a light scattering module specifically developed for ToF-AMS applications. The ToF-AMS has been widely used in laboratory and field studies and has been described in detail previously (DeCarlo et al., 2006; Drewnick et al., 2005; Jayne et al., 2000). The use of the LS-ToF-AMS for single-particle detection was first reported by Cross et al. (2009) with a compact ToFAMS system. The work reported here is the first time the LS module has been used to acquire single-particle data with a high-resolution ToF system (HR-ToF-AMS). Adding the light scattering module does not influence ToF-AMS performance but rather physically identifies all particles (both nonrefractory and refractory) that reach the vaporizer and are larger than the detection limit of the light scattering module, thereby providing substantially more information about single particles. During the entire campaign, the LS-ToFAMS was operated in the MS mode (measures ensemble average chemical composition), PToF mode (particle time-offlight, provides size-resolved chemical composition for ensemble average), and LSSP mode (acquires single-particle mass spectrum) for 120,120 and $80 \mathrm{~s}$ of approximately every $5 \mathrm{~min}$.

Briefly, the LS-ToF-AMS has five major components: aerosol sampling inlet, particle time-of-flight chamber, light scattering module for single-particle detection, particle vaporization and ionization chamber, and in this case a highresolution time-of-flight mass spectrometer. Aerosols sampled through a $100-\mu \mathrm{m}$ critical orifice are focused by an aerodynamic lens system, forming a narrow $(\sim 1 \mathrm{~mm}$ diameter) and highly collimated particle beam. Focused particles are transmitted under high vacuum $\left(\sim 10^{-5} \mathrm{~Pa}\right)$ through a laser beam for optical detection to the vaporization and ionization chamber, where they impact a heated surface $\left(\sim 600^{\circ} \mathrm{C}\right)$. The nonrefractory fractions of the particles are flash vaporized and ionized by electron impact. Orthogonally extracted ions are subsequently analyzed by a time-offlight mass spectrometer, which generates a complete mass spectrum at each extraction. A rotating chopper placed at the front of the particle-sizing chamber chops the particle beam and sets the starting time of particle flight. By measuring particle flight time between the mechanical chopper and the thermal vaporizer, particle vacuum aerodynamic diameter $\left(d_{\mathrm{va}}\right)$ can be determined from a calibration curve, which relates particle velocity (calculated using the known distance between the chopper and the vaporizer and the measured flight time) to particle size. The calibration curve was derived using polystyrene spheres (PSL of diameter $200 \mathrm{~nm}, 350 \mathrm{~nm}, 500 \mathrm{~nm}$, and $600 \mathrm{~nm}$ ) and ammonium nitrate particles that were size-selected by a differential 
Table 1. Comparison of single-particle measurement techniques and their detection limits.

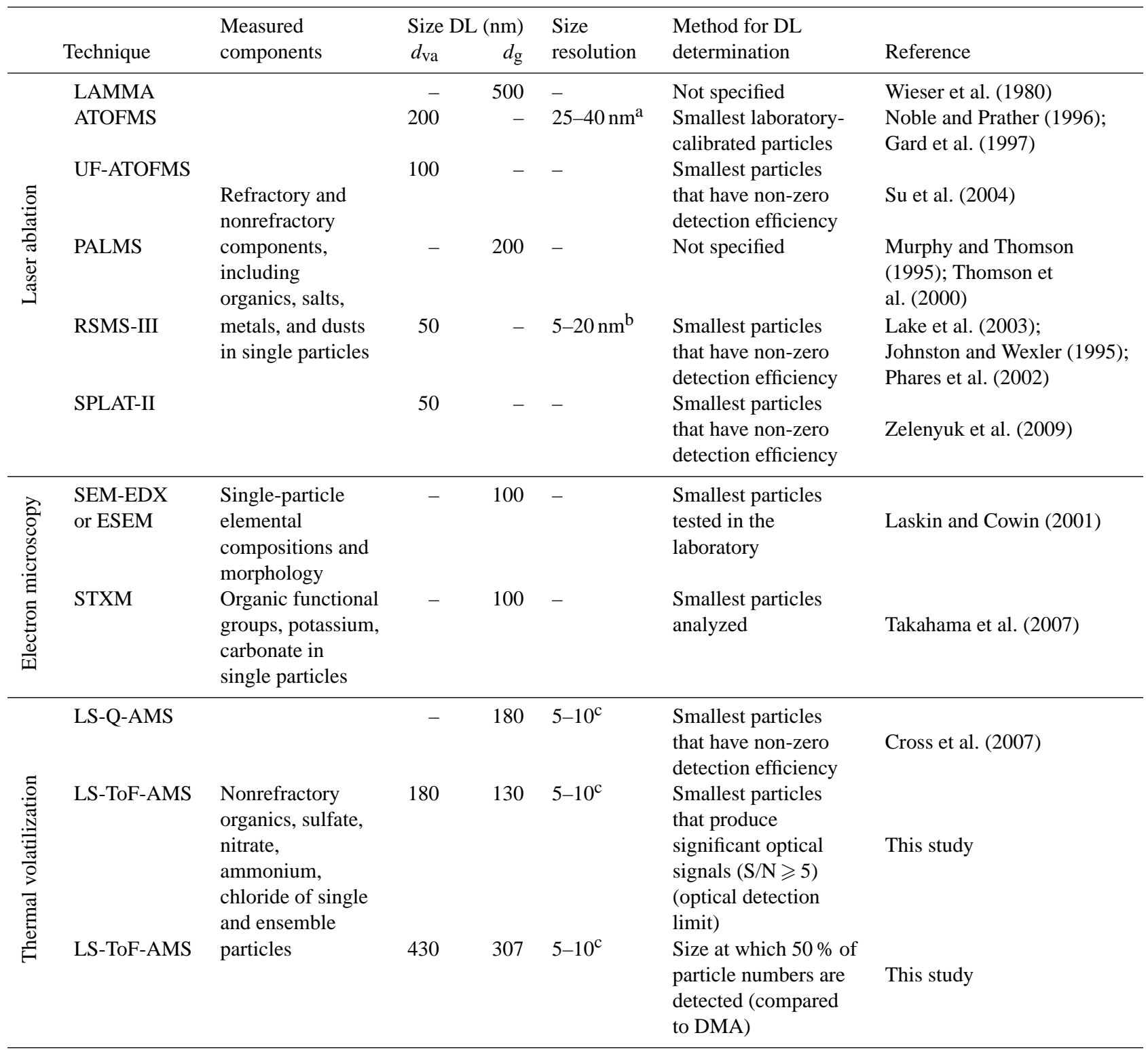

${ }^{a}$ Calculated as the standard deviation of the size-calibration curve fitting. ${ }^{b}$ Inferred from reported size distributions. ${ }^{\mathrm{c}}$ Calculated as $\mathrm{d} / \Delta \mathrm{d}$ at FWHM (full width at half maximum).

mobility analyzer (DMA). Comparison of nominal PSL size and mobility-selected size showed good agreement. In this study, geometric diameter $\left(d_{\mathrm{g}}\right)$ is calculated using $d_{\mathrm{va}}$ and particle density $\left(d_{\mathrm{g}}=d_{\mathrm{va}} / \rho\right)$, assuming spherical particles. The density $\left(1.4 \mathrm{~g} \mathrm{~cm}^{-3}\right)$ was derived by comparing AMSmeasured mass size distribution with SMPS (scanning mobility particle sizer)-measured volume size distributions detailed in Ahlm et al. (2012).

The laser used for optical detection was a 405-nm continuous wave 50-mW laser (CrystaLaser, LC BCL-050-405). In order to maximize the overlap of the laser and the particle beams, the laser beam was not focused (Cross et al.,
2007). Light scattered by sampled particles is collected using an ellipsoidal mirror and detected with a photomultiplier tube. The current system differs from the LS-ToF-AMS used by Cross et al. (2009) in the mechanism used for detecting single particles and saving the optical and chemical information for each detected particle. The key technical improvements include (1) adding the detected light scattering signal to the chopper frequency signal for unambiguous correlation in time, where the chopper frequency is the fundamental clock for the PToF and LSSP mode ToF-AMS data acquisition, and (2) using an external comparator circuit to test for the presence of a single particle in the scattered light signal, 
using a user set threshold level. This test is performed without transferring data to the computer for software evaluation, a process that takes more time than an individual chopper cycle. The comparator circuit triggers the saving of the mass spectral data. Once triggered, the DAQ reports individual mass spectra for the entire chopper period in which the LS event occurred (mass spectra obtained as a function of particle time-of-flight). This approach dramatically reduces the overhead associated with any data transfer for events where there are no particles and eliminates the need to transfer the data from the DAQ board to the computer for software detection of particles. The light scattering particle counter, which is part of the comparator circuit, counts all of the threshold crossers observed by the external comparator circuit in the LSSP, PToF, and MS modes. This includes LS pulses for which single-particle mass spectral data were not recorded due to the transfer and saving times. This counter provides a measure of the particle number concentration for all optically detected particles and allows for the accurate evaluation of the true duty cycle obtained by the LSSP mode and direct comparisons with independent aerosol instruments that measure particle number concentrations. In addition, the GZIP compression algorithm is applied to the single-particle files, thereby reducing the data transfer time and enhancing the sampling efficiency of the LS-ToF-AMS.

The LSSP mode records full mass spectra as a function of time during each chopper cycle. In the current configuration, there are 319 mass spectra obtained per chopper cycle. Each mass spectrum is baseline corrected to account for background signal at each $m / z$, using the average of two user selected "DC" regions at the start and end of the chopper cycle. Single-particle spectra are obtained by adding together a subset ( $\sim 5$ spectra) of the total number of baseline-corrected mass spectra collected during a single chopper cycle.

The chopper used during this study had a 0.02 duty cycle, and the chopper frequency was set to $143 \mathrm{~Hz}$ during the measurement. With this frequency, there is typically $\sim 1$ particle or less per chopper cycle on average (DeCarlo et al., 2006), allowing correlated measurements of single-particle light scattering and chemical compositions. Potential particle coincidence events were investigated by examining the light scattering profile (i.e., light scattering intensity as a function particle time-of-flight) for each LS event. Particle coincidence is identified as multiple crossing of thresholds, which are defined as 5 times the standard deviation of the baseline of the light scattering profile. Using this criterion, the number of particle coincidence events was $0.3 \%$ of the total particle events, suggesting that particle coincidence events are negligible. Particles in the coincidence events were excluded in the analysis.

The limiting issues with the LSSP mode include the typically low duty cycles of the chopper and the overhead associated with transferring and saving the mass spectral data for single particles (Kimmel et al., 2011). During the transferring and saving of mass spectral data for a single chopper cycle, data from the following 6 chopper cycles were not recorded. The resulting duty cycle due to data storage processes ranged from $\sim 0.14$ (i.e., 1/7 chopper cycles) to 1.0, depending upon the sampled particle number concentration, with an average of $\sim 0.62$ for this study. An additional duty cycle of 0.45 was present during this study due to an unusual noise spike (characterized by near-zero light scattering signals and were filtered out in single-particle analysis) in the LS channel that triggered saves. Taken together, the LSSP mode data rates obtained during this study represent a single-particle detection efficiency improvement of greater than a factor of 5 from the Cross et al. (2009) study.

\section{Results and discussion}

We began by classifying single particles into vaporization types based on timing of optically and chemically detected signals. We then clustered individual particle organic mass spectra with significant signals into groups, each of which is associated with distinct chemical signatures. Finally, we compared these single-particle groups with components extracted from ensemble measurements.

\subsection{Classification of single particles into vaporization types}

Light scattering and single-particle measurements were processed using an updated version of the standard AMS light scattering data processing software Sparrow 1.04A (written by D. Sueper, Aerodyne Research Inc. and University of Colorado at Boulder; available at http://cires.colorado.edu/jimenez-group/ ToFAMSResources/ToFSoftware/index.html\#Analysis4), which classifies the particles by their vaporization types and generates the physical (particle size in $d_{\mathrm{va}}$, light scattering intensity) and chemical (unit-mass spectrum and mass of organics, sulfate, nitrate, and ammonium) data of single particles. A total of 271641 particles were measured during the 46-day campaign. Figure 1a shows the time-integrated light scattering signals plotted versus $d_{\mathrm{va}}$ and $d_{\mathrm{g}}$ for all of the saved particles. The optical detection limit, defined as the size at which particles produce detectable optical signals $(\mathrm{S} / \mathrm{N} \geqslant 5)$, was $180 \mathrm{~nm} d_{\mathrm{va}}\left(130 \mathrm{~nm} d_{\mathrm{g}}\right)$. The optical detection efficiency, defined as the ratio of optically detected particle number concentrations to SMPS-measured number concentrations (Fig. 2b), dropped below $100 \%$ at $550 \mathrm{~nm}$ $d_{\mathrm{va}}\left(393 \mathrm{~nm} d_{\mathrm{g}}\right)$ and below $50 \%$ at $430 \mathrm{~nm} d_{\mathrm{va}}\left(307 \mathrm{~nm} d_{\mathrm{g}}\right)$. In comparison, the size that corresponds to $50 \%$ optical detection efficiency, derived from LS-coupled Q-AMS system in the laboratory by Cross et al. (2007), was $240 \mathrm{~nm} d_{\mathrm{g}}-$ $22 \%$ lower than $307 \mathrm{~nm} d_{\mathrm{g}}$, suggesting that the alignment of LS-ToF-AMS used in this study was less optimized than that of the Cross et al. laboratory study. A group of particles with relatively high organic mass fractions $(\sim 1)$ is distinct 


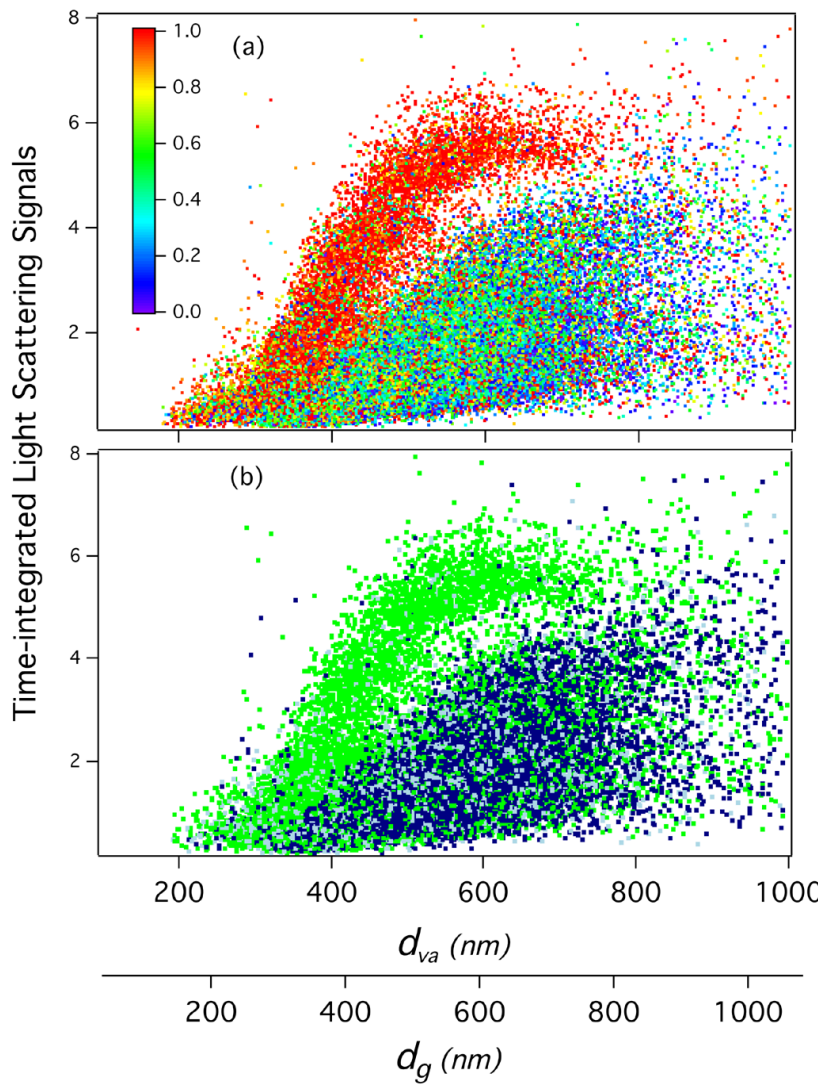

Fig. 1. Time-integrated light scattering signals of prompt and delayed particles as a function of $d_{\mathrm{va}}\left(d_{\mathrm{g}}\right)$. In (a), each particle is colored by its organic mass fraction with colors shown in the color bar. In (b), particles are colored by particle clusters derived from cluster analysis in Sect. 3.2. Only particles that have more than 40 ions are shown in (b). Colors indicate cluster I (dark blue), cluster II (light blue), and cluster III (green).

from the majority of the particles (Fig. 1a). This subset of particles is dominated by hydrocarbon-like organic aerosol (HOA) signals, has lower values of $d_{\mathrm{va}}$ and higher integrated scattering signals compared to the rest of the particles. As these particles that are classified in cluster III may consist of substantial primary OM (Fig. 1b and Sect. 3.2), these particles may contain black carbon or other primary refractory components that modified the shape, density, or the combined real refractive index of the particles. A similar, externally mixed, HOA-dominated particle type was observed in Mexico City and reported in Cross et al. (2009). However, more work needs to be done to fully characterize these particle types.

Total saved particles were scaled by overall duty cycle to derive average particle number size distribution for this study. The overall duty cycle accounted for the 0.02 chopper duty cycle, data transfer and saving duty cycle (ranged from $0.2-1.0$ with an average of 0.62 ), and noise spike duty cycle $(0.45)$. Figure $2 b$ represents the first direct in situ measure of the particle number-based sampling efficiency of an AMS and comparison with simultaneous SMPS numberbased measurements. The light scattering signals indicate that particle sampling efficiency for particle sizes greater than $550 \mathrm{~nm} d_{\mathrm{va}}\left(393 \mathrm{~nm} d_{\mathrm{g}}\right)$ is similar to the laboratory measurements for the aerodynamic inlet lens system, with decreasing transmission efficiency at larger particle sizes (Liu et al., 2007). Figure 2c shows the comparison of campaignaverage ion signals measured by the LSSP and PToF modes of the LS-ToF-AMS operation. Particles with time-of-flight greater than $0.0035 \mathrm{~s}$, corresponding to $600 \mathrm{~nm} d_{\mathrm{va}}$, showed good agreement between the LSSP mode and PToF mode measurements, consistent with the agreement of number concentrations for particles larger than $550 \mathrm{~nm} d_{\mathrm{va}}$ (Fig. 2b). Cross et al. (2009) demonstrated that the LSSP mode and PToF mode measured ion signals agreed for particles larger than $\sim 350 \mathrm{~nm} d_{\mathrm{va}}$, indicating that the LS system in that work was more optimized.

Low detection efficiency for small particles likely resulted from (i) widening of particle beam beyond the region of overlap of the particle and laser beams or low detection efficiency for small particles passing through the edges of the laser beam and (ii) size detection limit of small particles by the laser. Comparison of LS-ToF-AMS- and SMPS-measured total particle number concentration showed similar time series; i.e., total number concentration of 560- to $1000-\mathrm{nm} d_{\mathrm{va}}(400-$ to $715-\mathrm{nm} d_{\mathrm{g}}$ ) particles agreed reasonably well (Fig. S1) the linear fit has a slope of 0.89 (the SMPS-measured concentration was $11 \%$ higher) and an intercept of 6.25 , and the number concentrations correlated with an $R$ of 0.7 , while the total concentration of 200- to $560-\mathrm{nm} d_{\mathrm{va}}$ (140- to $400-\mathrm{nm}$ $d_{\mathrm{g}}$ ) particles measured by LS-ToF-AMS was much lower.

In order to determine the timing of the measured chemical signals, a mass intensity profile (i.e., mass intensity quantified by the ToF-MS mass spectrometer as a function of particle time-of-flight) is needed for each particle. The profile is the sum of profiles for all detected ion fragments (including organic and inorganic fragments) for each particle. Since the acquisition rate is faster than the particle vaporization time, several mass spectra are obtained during the $(\sim 100 \mu \mathrm{s})$ particle vaporization event. These individual spectra are co-added to accumulate the total measured ion intensity for the single particle. However, adding fragments with low intensities can significantly lower the contrast between real and background signals. Additionally, background-related fragments $m / z 18$ $\left(\mathrm{H}_{2} \mathrm{O}^{+}\right), 28\left(\mathrm{~N}_{2}{ }^{+}\right), 32\left(\mathrm{O}_{2}{ }^{+}\right)$, and $39\left(\mathrm{~K}^{+}\right)$can greatly mask real signals. Therefore, only the profiles of nonbackground high-intensity fragments were summed to construct a mass intensity profile for each particle.

Ensemble average concentrations (from the MS mode measurement) were used to estimate ion fragment abundance of single particles. Eleven high-intensity ion fragments were selected for this campaign, including $m / z 15,27$, 30, 41, 43, 44, 46, 48, 55, 57, and 64. This list combined organic- and inorganic- (nitrate, sulfate, and ammonium) 

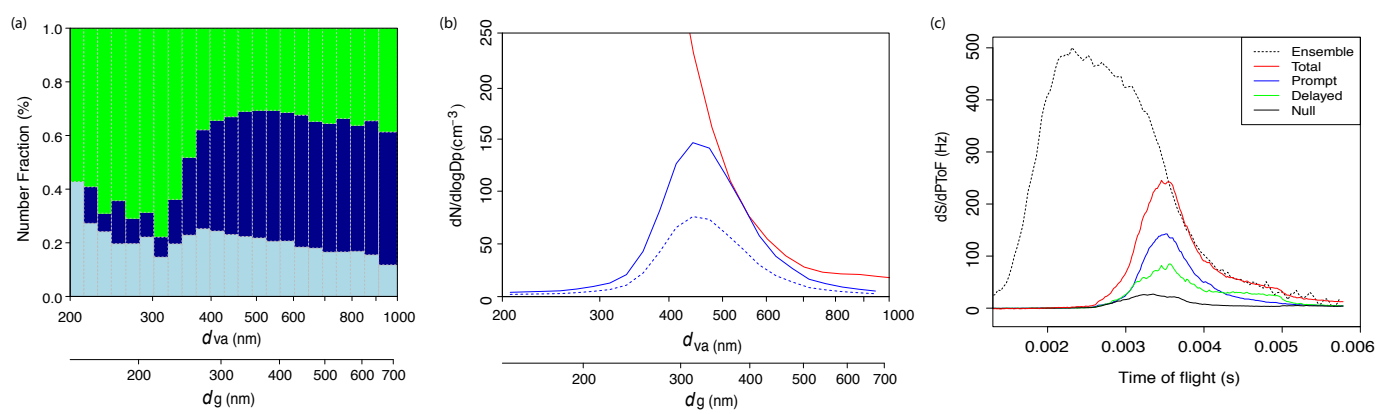

Fig. 2. (a) Number fractions for cluster I (dark blue), cluster II (light blue), and cluster III (green). (b) Particle number size distributions measured by SMPS (red) and LS-ToF-AMS (solid blue). A density of $1.4 \mathrm{~g} \mathrm{~cm}^{-3}$ was used to convert SMPS mobility diameter to $d_{\mathrm{va}}$ (Ahlm et al., 2012). Dashed blue line represents number size distribution for sum of prompt and delayed particles. Particle size is binned logarithmically. For each size bin, logarithmic ratio of upper size to lower size is 0.03 . (c) Comparison of campaign-average mass distribution as a function of particle time-of-flight of ensemble (dotted black line; PToF mode) and single-particle measurements (LSSP mode). The total (red) represents the sum of the prompt (blue), delayed (green), and null (black) particle signals measured by the LSSP mode.

dominated fragments. Additionally, selected organic fragments were characteristics of specific particle types; for example, $m / z 44$ is a tracer for oxygenated organic aerosols (OOA), and $m / z 57$ typically represents HOA (Zhang et al., 2005).

Timing of the optical signals ( $\left.T_{\mathrm{LS}}\right)$ and chemical signals $\left(T_{\mathrm{MS}}\right)$ was retrieved by locating the maximum light scattering intensity and mass intensity from the light scattering (i.e., light scattering intensity as a function of particle time-offlight) and mass intensity profiles, respectively. $T_{\mathrm{LS}}$ and $T_{\mathrm{MS}}$, respectively, represent the particle flight time from the midpoint of chopper opening to the laser and to the mass spectrometer (including the vaporization and ion transit time from the vaporizer to the time-of-flight mass spectrometer). Using the particle velocity (calculated from $T_{\mathrm{LS}}$ and the chopperto-laser distance) and the chopper-to-vaporizer distance, the timing of particle chemical signals can be predicted ( $\left.T_{\mathrm{MS} \_\mathrm{P}}\right)$. By comparing timing of the predicted particle chemical signals ( $\left.T_{\mathrm{MS} \_\mathrm{P}}\right)$ with the timing of the measured chemical signals $\left(T_{\mathrm{MS}}\right)$, the vaporization and ion flight time ( $\left.T_{\mathrm{MS} \_ \text {ION }}\right)$ can be estimated by the y-axis offset of the $T_{\mathrm{MS} P \mathrm{P}}$ versus $T_{\mathrm{MS}}$ (scatter) plot. Using $T_{\mathrm{MS}}$ and the sum of $T_{\mathrm{MS} \_\mathrm{P}}$ and $T_{\text {MS ION }}$, each single particle was classified as one of three discrete particle types: (1) "prompt," for which the deviation of $T_{\mathrm{MS}} /\left(T_{\mathrm{MS} \_\mathrm{P}}+T_{\mathrm{MS} \_ \text {ION }}\right)$ from 1 was less than $20 \%$ (i.e., particles optically and chemically detected at the expected time offset); (2) "delayed," for which the deviation of $T_{\mathrm{MS}} /\left(T_{\mathrm{MS} \_\mathrm{P}}+T_{\mathrm{MS} \_I O N}\right)$ from 1 was greater than $20 \%$ (i.e., $T_{\mathrm{MS}}$ significantly lagged $T_{\mathrm{MS} P \mathrm{P}}+T_{\mathrm{MS} \_ \text {ION }}$ ); and (3) "null," for which optical signals were detected, but no significant chemical signals were observed. The criterion of insignificant chemical signals is a minimum sum of chemical signals for the mass intensity profile of 6 ions. Using this criterion, the null particles had typically $2-4$ ions (Fig. S2) that are comparable to the number of ions generated in the nonparticle events (chopper cycles that have no particles).
Table 2. Particle number and number fraction for the three vaporization types.

\begin{tabular}{lrr}
\hline $\begin{array}{l}\text { Particle } \\
\text { vaporization type }\end{array}$ & $\begin{array}{r}\text { Particle } \\
\text { Number }\end{array}$ & $\begin{array}{r}\text { Number } \\
\text { fraction (\%) }\end{array}$ \\
\hline Prompt & 130361 & 46 \\
Delayed & 16996 & 6 \\
Null & 124284 & 48 \\
\hline
\end{tabular}

Particle statistics associated with the three vaporization types (Table 2) show that prompt and null particles dominated, accounting for $46 \%$ and $48 \%$, respectively, of the saved particles, while delayed particles accounted for a $6 \%$ fraction. The null particle fraction was comparable to that of the $51 \%$ fraction identified from the Mexico City measurement (Cross et al., 2009), suggesting that the AMS vaporization/ionization may typically miss about $50 \%$ of sampled particles (for particle diameters larger than $180 \mathrm{~nm} d_{\mathrm{va}}$ or $130 \mathrm{~nm} d_{\mathrm{g}}$ ), based on particle number. The prompt particle (46\%) group points to a number-based collection efficiency (CE) of $\sim 0.5$ for particles of 180-1000 $\mathrm{nm} d_{\mathrm{va}}(130-715 \mathrm{~nm}$ $d_{\mathrm{g}}$ ), which is lower than the average mass-based CE of 0.8 for particles smaller than $1000 \mathrm{~nm} d_{\mathrm{va}}$ in this study (Ahlm et al., 2012). This discrepancy likely results from particles that vaporize inside the AMS at rates too slow to be detected in the LSSP/PToF modes ( $\sim 6 \mathrm{~ms})$, but fast enough to be accounted for by the MS mode (10s). Further work is needed to resolve this discrepancy. CE values ranged from 0.43 to 0.52 for particles larger than $180 \mathrm{~nm} d_{\mathrm{va}}$, with peak values associated with 500-600 $\mathrm{nm} d_{\text {va }}$ particles (Fig. 3). Particles in 800- to $1000-\mathrm{nm} d_{\mathrm{va}}$ had the lowest CE values, likely due to enriched dust components in this size range (Silva et al., 2000) that were not vaporized by the AMS or because of the enhanced mass fraction of sulfate and decreased mass fraction of the organics (Fig. 1a). 


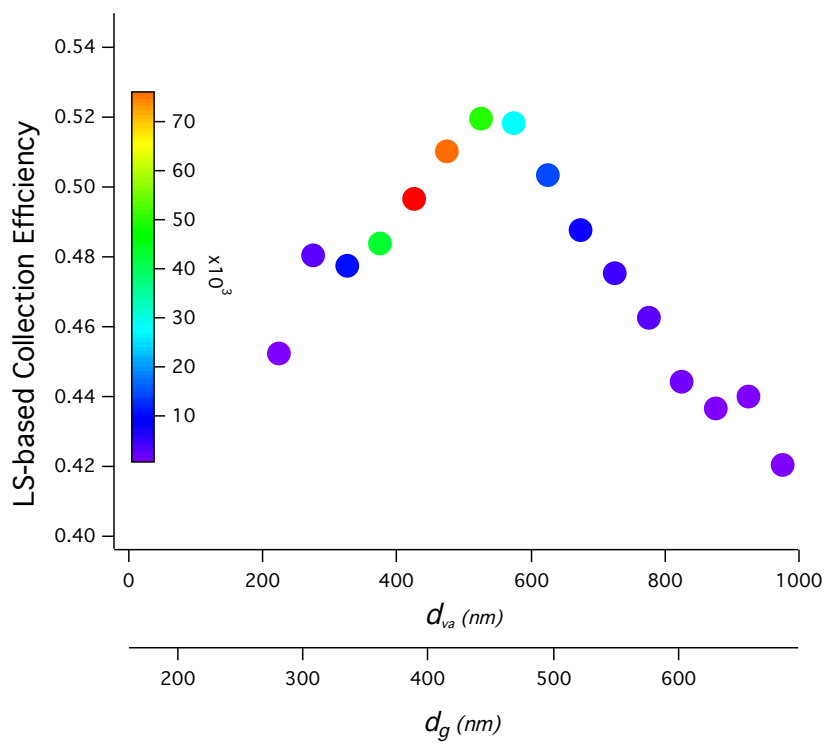

Fig. 3. LS-based collection efficiency versus particle size. Point colors indicate number of particles measured in the corresponding size, with color scale shown by the vertical bar.

\subsection{Organic particle types identified from cluster analysis}

Prompt and delayed particles that had significant mass spectrum signals (67 985 particles) were used for cluster analysis. The significant mass spectrum signals were defined as particle signals that have more than 40 ions. Including the particles with 6-40 ions decreases the robustness of the cluster analysis. Therefore, particles with less than 40 ions were excluded from the cluster analysis. The identification of 40 ions as a threshold of chemically meaningful particles is detailed in the Supplement. The $k$-means clustering algorithm divides spectra into $k$ clusters such that the sum of squares of the distances between the spectra and their corresponding cluster centroid is minimized (Hartigan and Wong, 1979). Spectra were normalized before clustering so that the sum of intensities for each mass spectrum was 1 . In order to identify organic particle types, only organic fragments were included in the cluster analysis. $k$ values of 2 to 12 (varying by 1 ) were tested. For each run, 20 sets of random cluster centroids were iterated. We have identified three major clusters termed as cluster I, cluster II, and cluster III (Supplement).

Cosine similarity is a useful tool for estimating mass spectrum similarity (Stein and Scott, 1994) and was therefore used here as a metric to measure the within-cluster and crosscluster similarity of single-particle spectra. In brief, cosine similarity is the cosine of the angle between two vectors (where each vector represents a mass spectrum) and is calculated using the following equation:

$\cos \theta=\frac{A \cdot B}{\|A\| \cdot\|B\|}=\sum_{i}^{n} A_{i} \times B_{i} /\left(\sqrt{\sum_{i}^{n}\left(A_{i}\right)^{2}} \times \sqrt{\sum_{i}^{n}\left(B_{i}\right)^{2}}\right)(1)$
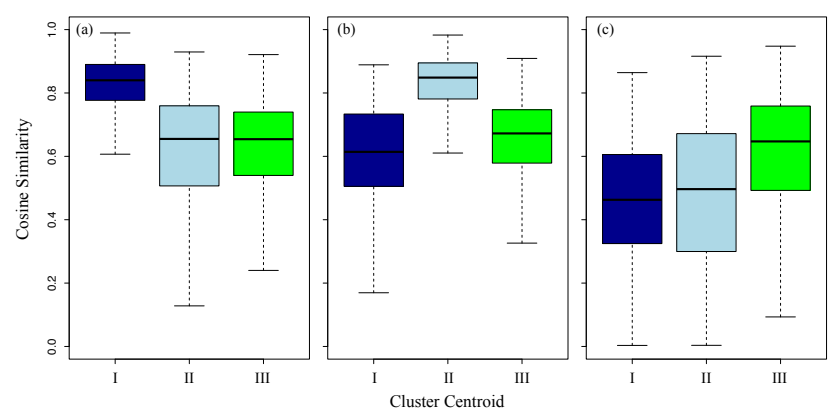

Fig. 4. Spectrum similarity to cluster I centroid (dark blue), cluster II centroid (light blue), and cluster III centroid (green) for (a) cluster I spectra, (b) cluster II spectra, and (c) cluster III spectra. The horizontal bar in each box represents the median value. Each box's upper and lower bounds represent the 25 th and the 75 th percentiles, respectively; the whiskers extend to 1.5 interquartile ranges.

where $\|A\|$ and $\|B\|$, respectively, represent the magnitudes of vectors $\boldsymbol{A}$ and $\boldsymbol{B}$, and $A \cdot B$ denotes the dot product of $\boldsymbol{A}$ and $\boldsymbol{B}$. Cosine similarity ranges from 0 to 1, with higher values representing smaller angles and higher similarity. The cosine similarity between each single-particle spectrum and the three major cluster centroids (the average spectra) was calculated (Fig. 4). Spectra in cluster I had significantly higher similarity (median value is $>0.8$ ) to cluster I centroid than cluster II and III centroids (Fig. 4a). In other words, the within-cluster similarity was far higher than the cross-cluster similarity for cluster I spectra. In addition, the variability of the within-cluster similarity was lower than that of the cross-cluster similarity, suggesting good separation of cluster I spectra. Similar results were found for cluster II spectra (Fig. 4b). Compared to cluster I and cluster II, the within-cluster similarity for cluster III spectra had lower values (median value of $\sim 0.65$ ) and greater variability (Fig. 4c). However, the within-cluster similarity was significantly higher than the cross-cluster similarity at $99 \%$ confidence level for cluster III spectra. The cosine similarity analysis also suggests that each cluster may have limited chemical properties of other clusters, indicating that particles were likely internally mixed but dominated by one type so they can be grouped by the dominant signatures.

The effects of single-particle size and organic mass fraction on the derived single-particle clusters were examined. The number of organic ions detected for each single-particle is a function of the organic mass fraction (for a given threshold of 40 ions) and particle size (larger particles produce more ions). Sulfate and nitrate, the major inorganic ions, were found to be independent of organic cluster types (Fig. 5); i.e., sulfate and nitrate, respectively, accounted for $16 \%$ and $4 \%$ of single-particle mass for each cluster (on average). To test the effects of organic mass fractions on the derived clusters, a $k$-means algorithm was applied to four subsets of the total 67985 particles, which were composed of particles with organic mass fractions greater than $10 \%$, 


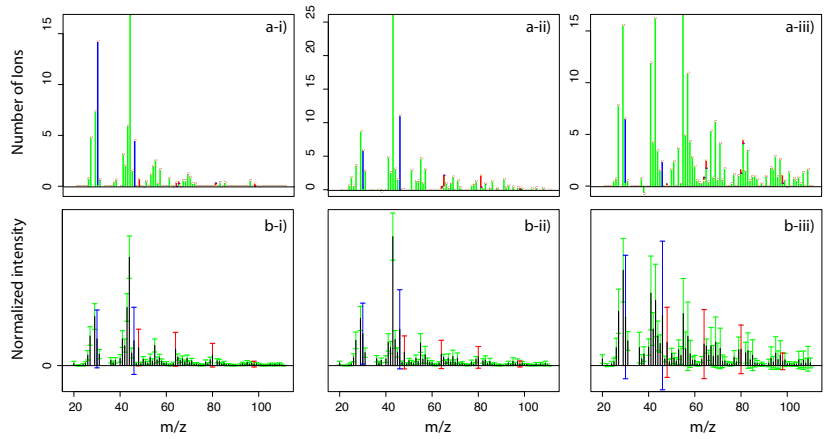

Fig. 5. (a) Example single-particle spectra for (i) cluster I, (ii) cluster II, and (iii) cluster III. The particles in (i), (ii), and (iii) were collected on 16 May $\left(d_{\mathrm{va}}=507 \mathrm{~nm}, d_{\mathrm{g}}=362 \mathrm{~nm}\right), 31$ May $\left(d_{\mathrm{va}}=\right.$ $\left.402 \mathrm{~nm}, d_{\mathrm{g}}=287 \mathrm{~nm}\right)$, and 16 May $\left(d_{\mathrm{va}}=492 \mathrm{~nm}, d_{\mathrm{g}}=351 \mathrm{~nm}\right)$, respectively. (b) Variability of normalized single-particle spectra for each cluster for this study (15 May to 29 June 2010). In each panel, the black sticks show the average spectrum for the cluster, and the whiskers represent standard deviations (variability) at each $m / z$. Colors indicate organic (green), nitrate (blue), and sulfate (red) fragments.

$20 \%, 30 \%$, and $40 \%$ of the total particle mass, respectively. Three major clusters were identified in each case. The cluster centroids were identical to the centroids of clusters I to III, and the relative cluster sizes (number of particles in the cluster) were comparable to the relative sizes of clusters I to III, indicating that the same single-particle clusters were identified. The effects of particle size on clustering results were tested by applying a $k$-means analysis to three subsets of the total particles, which were composed of particles larger than $300 \mathrm{~nm}, 400 \mathrm{~nm}$, and $500 \mathrm{~nm} d_{\mathrm{va}}$, respectively. The same clusters (as clusters I to III) were identified. That the inorganic-to-organic mass ratio and particle size did not affect the results of cluster analysis indicated that the singleparticle organic mass ions were sufficient for cluster analysis and the identified clusters were robust.

Examples of single-particle spectra for the three major clusters are shown in Fig. 5a. While the single-particle spectra exhibit large variability (Fig. 5b), the centroids for the three particle types (Fig. 6a) show that the cluster I spectrum was characterized by a dominant peak at $m / z 44$, comparable to that of LV-OOA (low-volatility OOA) components extracted from the positive matrix factorization (PMF) analysis in a number of field measurements (Ulbrich et al., 2009). This indicates that particles in this cluster were highly oxidized and associated with high $\mathrm{O} / \mathrm{C}$, which is consistent with the correlation of the number fraction of cluster I particles with odd oxygen (Fig. 7a). It is suggested that cluster II particles, which had strong $m / z 43$ signals and mass spectra resembling those of SV-OOA (semi-volatile OOA) components identified by Lanz et al. (2007), Ng et al. (2010), and Ulbrich et al. (2009), were relatively less oxidized secondary organic aerosol (SOA) and, so, were likely associated with

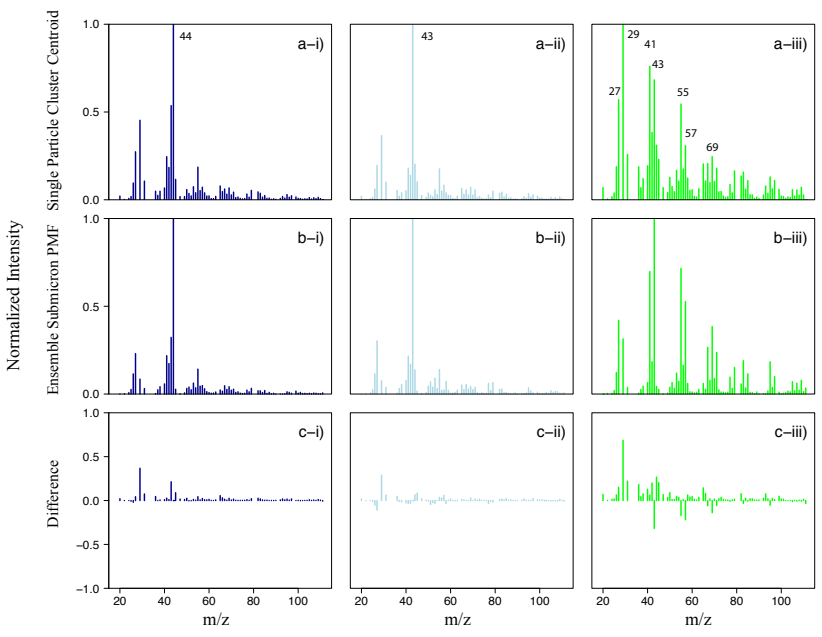

Fig. 6. (a) Cluster centroid (group-average mass spectrum) for (i) cluster I, (ii) cluster II, and (iii) cluster III particles. (b) Mass spectrum for (i) the high $\mathrm{O} / \mathrm{C}$ alkane SOA factor, (ii) the low $\mathrm{O} / \mathrm{C}$ alkane SOA factor, and (iii) mass-weighted average for the COA, PO SOA, and nighttime $\mathrm{OA}$ factors identified from the ensemble measurements using PMF analysis. (c) The difference between spectra in (a) and (b).

lower $\mathrm{O} / \mathrm{C}$ than cluster I particles. The number fraction of cluster II particles increased at night and showed the opposite diurnal cycle to temperature (Fig. 7b), which is consistent with the previous findings that the less processed component accumulated and condensed onto preexisting particles during nighttime hours (Lanz et al., 2007). However, the correlation of cluster II particle number fraction with particle-phase nitrate, whose formation is strongly dependent on temperature, was not found, suggesting that there might be other factors that affected the formation of cluster II particles. The average spectrum for cluster III particles was characterized by $m / z 27,29,41,43,55,57$, and 69 , which are characteristic of both HOA and cooking organic aerosol (COA) components (He et al., 2010; Mohr et al., 2009, 2012). However, the HOA and COA components are not distinguishable due to the high similarity of their unit-mass spectra (Mohr et al., 2009, 2012), although both the HOA-influenced component (the nighttime OA factor) and the COA component were identified from the PMF analysis of the high-resolution ensemble mass spectra measured by the same LS-ToF-AMS during the CalNex campaign (Liu et al., 2012). The number fraction of cluster III particles peaked at night, anti-correlating with temperature (Fig. 7c). Thus particles in cluster III may be produced by a mixture of different sources, possibly including cooking oils and local unoxidized vehicular emissions at night.

Size distributions of particle types (Fig. 2a) show an increased number fraction of cluster I type for particles larger than $300 \mathrm{~nm} d_{\mathrm{va}}\left(215 \mathrm{~nm} d_{\mathrm{g}}\right)$. In contrast, cluster III type dominated particles smaller than $400 \mathrm{~nm} d_{\mathrm{va}}\left(285 \mathrm{~nm} d_{\mathrm{g}}\right)$. 


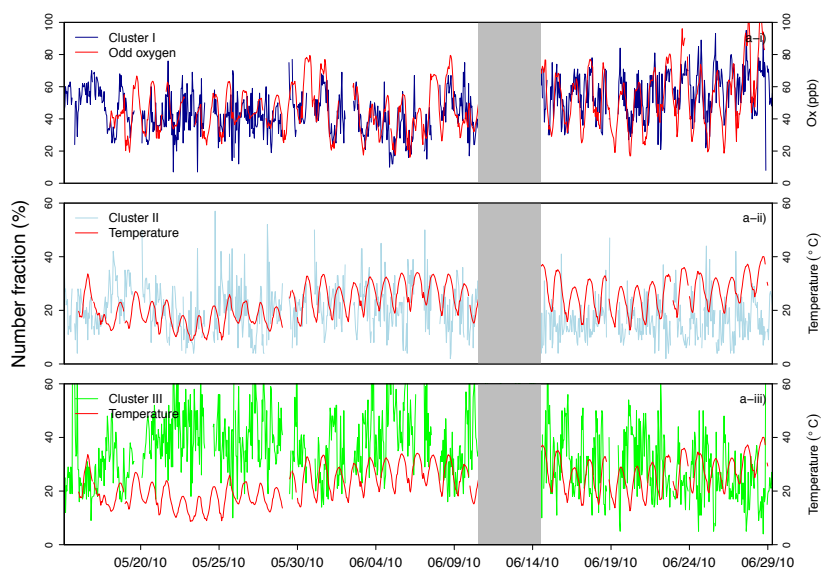

Fig. 7. Time series of the number fraction for (i) cluster I (dark blue), (ii) cluster II (light blue), and cluster III (green) particles. Time series of odd oxygen $\left(\mathrm{O}_{x}\right.$, shown in panel i) and temperature (panel ii and iii) are shown for comparison.

Compared to cluster I and cluster III particle types, cluster II type was more evenly distributed across particle size. A likely explanation of size dependence of particle types is that oxidized particles (in cluster I) formed by condensation of secondary vapors onto preexisting particles so that they grew bigger, whereas cluster III particles were associated with fresh emissions in which particles were smaller.

\subsection{Comparison of single-particle types with ensemble components}

Cluster I, cluster II, and cluster III particle types broadly matched the OM components identified from ensemble factor analysis using PMF (Liu et al., 2012). Ensemble-based OM spectra were categorized into three groups according to their $\mathrm{O} / \mathrm{C}$-values (calculated from the high-resolution mass spectra using the method described by Aiken et al., 2007): Group I consisted of high O/C alkane and aromatic SOA components $(\mathrm{O} / \mathrm{C}=0.63-0.68)$; group II consisted of low $\mathrm{O} / \mathrm{C}$ alkane and aromatic SOA components $(\mathrm{O} / \mathrm{C}=0.27-$ 0.36 ); and group III was likely a mixture of COA, petroleum operation (PO) SOA, and local traffic and biogenic nighttime OA components $(\mathrm{O} / \mathrm{C}=0.00-0.20)$. The mass fractions of $\mathrm{m} / \mathrm{z}_{4} 4$ ( $f_{44}$; an indicator of $\mathrm{O} / \mathrm{C}$; Aiken et al., 2008) for cluster I $(20.8 \%)$, cluster II $(5.0 \%)$, and cluster III $(3.0 \%)$ reasonably agreed with the $f_{44}$ for the ensemble-based group I $(19.6 \%)$, group II $(2.4 \%)$, and group III $(0.5 \%)$, respectively. Specifically, the cluster I centroid correlated to the mass spectra for high $\mathrm{O} / \mathrm{C}$ alkane and aromatic SOA components with an $R$ of 0.96 and 0.92 , respectively (Fig. 6). The mass fraction of cluster I particles had similar magnitude and time series to that of the sum of high $\mathrm{O} / \mathrm{C}$ alkane and aromatic SOA components (Fig. 8a; correlated in time with $R=0.69$ shown in Table S1), supporting the consistency of cluster I particles with high $\mathrm{O} / \mathrm{C}$ components. The

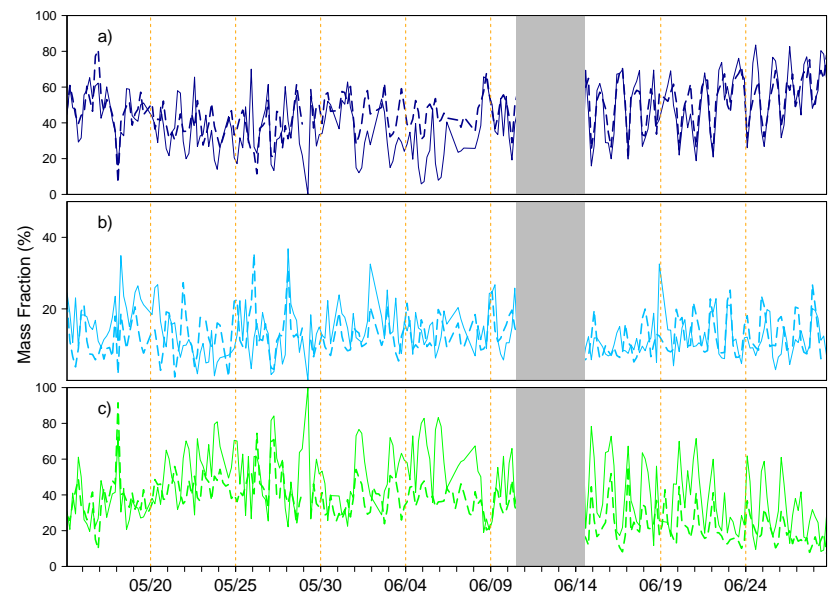

Fig. 8. Solid lines show time series of the mass fraction for (a) cluster I (dark blue), (b) cluster II (light blue), and (c) cluster III (green) particles. Dashed lines represent time series of the mass fraction for (a) the sum of high O/C alkane and aromatic SOA (dark blue), (b) the low O/C alkane SOA (light blue), and (c) the sum of COA, PO SOA, and nighttime OA factors (green) identified from ensemble measurements using PMF analysis (Liu et al., 2012). Measurements were averaged to 4 -h intervals.

centroid for cluster II particles correlated to that of the low O/C alkane SOA component with an $R$ of 0.96 . The cluster III centroid correlated to the spectra for COA, PO SOA, and nighttime OA components with $R$ values of $0.86,0.76$, and 0.70 , respectively. Correlation of the cluster III centroid to the mass-weighted average spectrum for COA, PO SOA and nighttime OA (Fig. 6b-iii) showed an $R$ of 0.88 . The mass fraction of cluster III particles and the sum of ensemblederived group III components co-varied (Fig. 8c; $R=0.60$ shown in Table S1), with low fractions during daytime and increased abundance at night. There were some deviations in magnitude and time series for single-particle clusters and ensemble-derived components, especially for cluster II particles that only poorly correlated with the low $\mathrm{O} / \mathrm{C}$ alkane SOA factor $(R=0.23)$. The differences were likely due to (1) measurement and analysis (cluster, PMF, etc.) uncertainties, (2) internally mixed particles that were split between more than one cluster, or (3) the low detection efficiency of single particles that were smaller than $550 \mathrm{~nm} d_{\mathrm{va}}$ (Fig. 2b). However, the broad match of single-particle clusters and ensemble factors confirmed that the factors reflected organic components of different origins and atmospheric processes.

\section{Concluding remarks}

The LS-ToF-AMS was valuable for separating single particles with different organic chemical compositions in a 46day field campaign. 271641 single particles were optically detected and the chemical mass spectra saved and classified by comparison of the optical and chemical information, with 
a $46 \%$ prompt fraction, a $48 \%$ null fraction, and a $6 \%$ delayed particle fraction. Thus, the LS-ToF-AMS provided a direct measure of the collection efficiency of ambient particles, resulting in an approximate $50 \%$ number-based CE for particles larger than $180 \mathrm{~nm} d_{\mathrm{va}}\left(130 \mathrm{~nm} d_{\mathrm{g}}\right)$.

Single particles can be consistently represented by several particle types, each of which has distinct chemical compositions formed via different processes. A $k$-means clustering algorithm was applied to the organic mass spectra for prompt and delayed single particles that have sufficient chemical ions. We found that the single particles were dominated by chemical characteristics of one of the three clusters: Cluster I and II particles appeared to be formed from secondary organic components, while cluster III particles suggested a primary origin from fresh urban emissions. Additionally, cluster I particles likely were more oxidized than particles in cluster II due to the large contribution of $m / z 44$ in the cluster I centroid. Mass spectra and time series of the three particle types broadly matched the organic factors identified from the ensemble-averaged measurements using the LS-ToF-AMS, providing evidence that the factors could represent organic components originating from different sources and processes.

Continual developments of LS-ToF-AMS, such as enhancing its ability to detect smaller particles and data transfer and saving efficiency, will result in more detailed information about the origin, transformation, and fate of atmospheric organic particles.

\section{Supplementary material related to this article is available online at: http://www.atmos-meas-tech.net/6/ 187/2013/amt-6-187-2013-supplement.pdf.}

Acknowledgements. This work was supported by California Air Resources Board (CARB), under contract 09-328. The authors appreciate great efforts of Douglas Day for helping with instrument operation, maintenance, and data collection. The authors are grateful to the CalNex-SJV research team, in particular Ron Cohen and Allen Goldstein who organized the campaign and Sally Pusede for coordination. John Karlik and the Kern County University of California Cooperative Extension staff hosted the field site, and their generous help is appreciated. The authors also thank John Jayne and Joel Kimmel for constructive comments. The statements and conclusions in this paper are those of the researchers (contractor) and not necessarily those of CARB. The mention of commercial products, their source, or their use in connection with material reported herein is not to be construed as actual or implied endorsement of such products.

Edited by: J. Abbatt

\section{References}

Ahlm, L., Liu, S., Day, D. A., Russell, L. M., Weber, R., Gentner, D. R., Goldstein, A. H., DiGangi, J. P., Henry, S. B., Keutsch, F. N., VandenBoer, T. C., Markovic, M. Z., Murphy, J. G., Ren, X., and Scheller, S.: Formation and growth of ultrafine particles from secondary sources in bakersfield, california, J. Geophys. Res.Atmos., 117, D00V08, doi:10.1029/2011JD017144, 2012.

Aiken, A. C., DeCarlo, P. F., and Jimenez, J. L.: Elemental analysis of organic species with electron ionization high-resolution mass spectrometry, Anal. Chem., 79, 8350-8358, 2007.

Aiken, A. C., Decarlo, P. F., Kroll, J. H., Worsnop, D. R., Huffman, J. A., Docherty, K. S., Ulbrich, I. M., Mohr, C., Kimmel, J. R., Sueper, D., Sun, Y., Zhang, Q., Trimborn, A., Northway, M., Ziemann, P. J., Canagaratna, M. R., Onasch, T. B., Alfarra, M. R., Prevot, A. S. H., Dommen, J., Duplissy, J., Metzger, A., Baltensperger, U., and Jimenez, J. L.: O/c and om/oc ratios of primary, secondary, and ambient organic aerosols with high-resolution time-of-flight aerosol mass spectrometry, Environ. Sci. Technol, 42, 4478-4485, 2008.

Cross, E. S., Slowik, J. G., Davidovits, P., Allan, J. D., Worsnop, D. R., Jayne, J. T., Lewis, D. K., Canagaratna, M., and Onasch, T. B.: Laboratory and ambient particle density determinations using light scattering in conjunction with aerosol mass spectrometry, Aerosol Sci. Tech., 41, 343-359, 2007.

Cross, E. S., Onasch, T. B., Canagaratna, M., Jayne, J. T., Kimmel, J., Yu, X.-Y., Alexander, M. L., Worsnop, D. R., and Davidovits, P.: Single particle characterization using a light scattering module coupled to a time-of-flight aerosol mass spectrometer, Atmos. Chem. Phys., 9, 7769-7793, doi:10.5194/acp-9-7769-2009, 2009.

DeCarlo, P. F., Kimmel, J. R., Trimborn, A., Northway, M. J., Jayne, J. T., Aiken, A. C., Gonin, M., Fuhrer, K., Horvath, T., Docherty, K. S., Worsnop, D. R., and Jimenez, J. L.: Field-deployable, high-resolution, time-of-flight aerosol mass spectrometer, Anal. Chem., 78, 8281-8289, 2006.

Drewnick, F., Hings, S. S., DeCarlo, P., Jayne, J. T., Gonin, M., Fuhrer, K., Weimer, S., Jimenez, J. L., Demerjian, K. L., Borrmann, S., and Worsnop, D. R.: A new time-of-flight aerosol mass spectrometer (tof-ams) - instrument description and first field deployment, Aerosol Sci. Tech., 39, 637-658, 2005.

Gard, E., Mayer, J. E., Morrical, B. D., Dienes, T., Fergenson, D. P., and Prather, K. A.: Real-time analysis of individual atmospheric aerosol particles: Design and performance of a portable atofms, Anal. Chem., 69, 4083-4091, 1997.

Hartigan, J. A. and Wong, M. A.: A k-means clustering algorithm, Appl. Stat., Vol. 28, 1979.

He, L.-Y., Lin, Y., Huang, X.-F., Guo, S., Xue, L., Su, Q., Hu, M., Luan, S.-J., and Zhang, Y.-H.: Characterization of highresolution aerosol mass spectra of primary organic aerosol emissions from Chinese cooking and biomass burning, Atmos. Chem. Phys., 10, 11535-11543, doi:10.5194/acp-10-11535-2010, 2010.

Jayne, J. T., Leard, D. C., Zhang, X. F., Davidovits, P., Smith, K. A., Kolb, C. E., and Worsnop, D. R.: Development of an aerosol mass spectrometer for size and composition analysis of submicron particles, Aerosol Sci. Tech., 33, 49-70, 2000.

Johnston, M. V. and Wexler, A. S.: Ms of individual aerosol particles, Anal. Chem., 67, 721-726, 1995.

Kimmel, J. R., Farmer, D. K., Cubison, M. J., Sueper, D., Tanner, C., Nemitz, E., Worsnop, D. R., Gonin, M., and Jimenez, J. L.: Real- 
time aerosol mass spectrometry with millisecond resolution, Int. J. Mass Sp., 303, 15-26, 2011.

Lake, D. A., Tolocka, M. P., Johnston, M. V., and Wexler, A. S.: Mass spectrometry of individual particles between 50 and $750 \mathrm{~nm}$ in diameter at the baltimore supersite, Environ. Sci. Technol., 37, 3268-3274, 2003.

Lanz, V. A., Alfarra, M. R., Baltensperger, U., Buchmann, B., Hueglin, C., and PrÉvôt, A. S. H.: Source apportionment of submicron organic aerosols at an urban site by factor analytical modelling of aerosol mass spectra, Atmos. Chem. Phys., 7, 15031522, doi:10.5194/acp-7-1503-2007, 2007.

Laskin, A. and Cowin, J. P.: Automated single particle sem/edx analysis of submicrometer particles down to $0.1 \mu \mathrm{m}$, Anal. Chem., 73, 1023-1029, 2001.

Liu, P. S. K., Deng, R., Smith, K. A., Williams, L. R., Jayne, J. T., Canagaratna, M. R., Moore, K., Onasch, T. B., Worsnop, D. R., and Deshler, T.: Transmission efficiency of an aerodynamic focusing lens system: Comparison of model calculations and laboratory measurements for the aerodyne aerosol mass spectrometer, Aerosol Sci. Tech., 41, 721-733, 2007.

Liu, S., Ahlm, L., Day, D. A., Russell, L. M., Zhao, Y., Gentner, D. R., Weber, R. J., Goldstein, A. H., Jaoui, M., Offenberg, J. H., Kleindienst, T. E., Rubitschun, C., Surratt, J. D, Sheesley, R. J., and Scheller, S.: Secondary organic aerosol formation from fossil fuel sources contribute majority of summertime organic mass at Bakersfield, J. Geophys. Res. Atmos., 117, D00V26, doi:10.1029/2012JD018170, 2012.

Mohr, C., Huffman, J. A., Cubison, M. J., Aiken, A. C., Docherty, K. S., Kimel, J. R., Ulbrich, I. M., Hannigan, M., and Jimenez, J. L.: Characterization of Primary Organic Aerosol Emissions from Meat Cooking, Trash Burning, and Motor Vehicles with HighResolution Aerosol Mass Spectrometry and Comparison with Ambient and Chamber Observations, Environ. Sci. Technol., 43, 2443-2449, 2009.

Mohr, C., DeCarlo, P. F., Heringa, M. F., Chirico, R., Slowik, J. G., Richter, R., Reche, C., Alastuey, A., Querol, X., Seco, R., Peñuelas, J., Jiménez, J. L., Crippa, M., Zimmermann, R., Baltensperger, U., and Prévôt, A. S. H.: Identification and quantification of organic aerosol from cooking and other sources in Barcelona using aerosol mass spectrometer data, Atmos. Chem. Phys., 12, 1649-1665, doi:10.5194/acp-12-1649-2012, 2012.

Murphy, D. M. and Thomson, D. S.: Laser ionization massspectroscopy of single aerosol-particles, Aerosol Sci. Tech., 22, 237-249, 1995.

Ng, N. L., Canagaratna, M. R., Zhang, Q., Jimenez, J. L., Tian, J., Ulbrich, I. M., Kroll, J. H., Docherty, K. S., Chhabra, P. S., Bahreini, R., Murphy, S. M., Seinfeld, J. H., Hildebrandt, L., Donahue, N. M., DeCarlo, P. F., Lanz, V. A., Prévôt, A. S. H., Dinar, E., Rudich, Y., and Worsnop, D. R.: Organic aerosol components observed in Northern Hemispheric datasets from Aerosol Mass Spectrometry, Atmos. Chem. Phys., 10, 46254641, doi:10.5194/acp-10-4625-2010, 2010.
Noble, C. A. and Prather, K. A.: Real-time measurement of correlated size and composition profiles of individual atmospheric aerosol particles, Environ. Sci. Technol., 30, 2667-2680, 1996.

Phares, D. J., Rhoads, K. P., and Wexler, A. S.: Performance of a single ultrafine particle mass spectrometer, Aerosol Sci. Tech., 36, 583-592, 2002.

Silva, P. J., Carlin, R. A., and Prather, K. A.: Single particle analysis of suspended soil dust from Southern California, Atmos. Environ., 34, 1811-1820, 2000.

Stein, S. E. and Scott, D. R.: Optimization and testing of massspectral library search algorithms for compound identification, J. Am. Soc. Mass Spectr., 5, 859-866, 1994.

Su, Y. X., Sipin, M. F., Furutani, H., and Prather, K. A.: Development and characterization of an aerosol time-of-flight mass spectrometer with increased detection efficiency, Anal. Chem., 76, 712-719, 2004.

Takahama, S., Gilardoni, S., Russell, L. M., and Kilcoyne, A. L. D.: Classification of multiple types of organic carbon composition in atmospheric particles by scanning transmission x-ray microscopy analysis, Atmos. Environ., 41, 9435-9451, 2007.

Thomson, D. S., Schein, M. E., and Murphy, D. M.: Particle analysis by laser mass spectrometry wb-57f instrument overview, Aerosol Sci. Tech., 33, 153-169, 2000.

Ulbrich, I. M., Canagaratna, M. R., Zhang, Q., Worsnop, D. R., and Jimenez, J. L.: Interpretation of organic components from Positive Matrix Factorization of aerosol mass spectrometric data, Atmos. Chem. Phys., 9, 2891-2918, doi:10.5194/acp-9-2891-2009, 2009.

Wieser, P., Wurster, R., and Seiler, H.: Identification of airborne particles by laser-induced mass-spectroscopy, Atmos. Environ., 14, 485-494, 1980.

Zelenyuk, A., Yang, J., Choi, E., and Imre, D.: Splat ii: An aircraft compatible, ultra-sensitive, high precision instrument for in-situ characterization of the size and composition of fine and ultrafine particles, Aerosol Sci. Tech., 43, 411-424, 2009.

Zhang, Q., Alfarra, M. R., Worsnop, D. R., Allan, J. D., Coe, H., Canagaratna, M. R., and Jimenez, J. L.: Deconvolution and quantification of hydrocarbon-like and oxygenated organic aerosols based on aerosol mass spectrometry, Environ. Sci. Technol., 39, 4938-4952, 2005. 